60 lines and 20 pictures per second. In Los Angeles, the 17 local broadcast stations, several of which are ' on the air' for 24 hours daily, made reception from other cities practically impossible, but a number of international relays from abroad were heard from them. The B.B.C. orchestra was heard as distinctly as it is in London. When passing through the Japanese and Mexican portion of the city, the street resounded with a speech from Berlin. In Tennessee, near Nashville, Los Angeles, 1775 miles to the west, and New York, 775 miles to the east, could be heard easily on the portable receiver. The writer mentions that Los Angeles (KFI), Dallas (WFAA), and Cincinnati (WLW) transmitted splendidly. In daytime they could be heard at a distance of 300 miles in good volume, and at night at distances of more than 1000 miles. When he got back to Pennsylvania, he heard at 7 A.M. the toasts given at the Lindbergh banquet at Tokyo (9 P.M. in Japan) being relayed from the local networks.

\section{U1tra-short Wave Television}

A sUCCESSFul public demonstration of ultra-short wave television was given on Friday, April 29, at Messrs. Selfridges' stores in Oxford Street, London. The transmitter was situated on the roof of the laboratories of Baird Television, Ltd., in Long Acre, W.C.2, the wave-length used being $6 \cdot 1$ metres. The ultra-short waves have the advantage over medium wave-lengths that they allow television pictures of much finer detail to be transmitted, and provide a reliable local service free from fading and atmospheric disturbances. An interesting feature of the transmission was that although sent out on ultra-short waves, the images could still be received easily by possessors of the ordinary Baird 'Televisor' and wireless sets of normal type designed for the present B.B.C. television transmissions. To do this, the only extra apparatus required was an ultra-short wave adaptor, which virtually converts any normal receiver into a super-heterodyne. The demonstration given on April 29 is the first public demonstration of the possibilities of ultra-short wave television to be given anywhere in the world, and marks a further stage in the development of the art.

\section{Developments in Methods of Communication}

A PAPER on modern communication systems, by Dr. F. Lüschen, was read to the Institution of Electrical Engineers on April 7. Dr. Lüschen pointed out that the rapid progress of invention has made modern communication systems very complicated to design. Few realise how difficult it was to solve the problem of the interconnexion of wired and wireless systems. This was first carried out in the telephone link between Great Britain and the United States. Further problems that have been solved are the multiple utilisation of lines for telegraphy and telephony, the control of electrical apparatus at a distance, and the electro-acoustic transmission problems involved in broadcasting and sound-films. These methods have widely extended the field of use of communication systems. The information contained in the spoken word is an extremely complicated function of the time. The transmission system is composed of widely different elements. At first, therefore, it appears to be a hopelessly difficult problem. Yet, with the help of a few simple mathematical principles, engineers have succeeded in visualising the transmission of signals. As an illustration of the pitch of perfection to which carriercurrent telephony has reached in the United States, Dr. Lüschen described a pole line carrying twenty pairs of conductors, sixteen of which carry three high frequency channels each, in addition to their low frequency communication circuits, while the other four pairs are equipped with ten telegraph channels each. Twenty pairs of wires thus result in 150 communication circuits, 80 of them being telegraph circuits and 70 of them telephone circuits. Dr. Lüschen also gave interesting particulars of tests made on a system of telephony and telegraphy linking Berlin with Buenos Aires. It is designed to transmit speech and two telegraphic messages simultaneously.

\section{Rival Theories of Hearing}

Is his Royal Institution discourse on Friday, April 29, on theories of hearing, Prof. H. Hartridge reminded his listeners that rivalry still exists between the theories of hearing, because the small size, the delicacy, and the inaccessibility of the internal ear make direct observation and experimentation wellnigh impossible. Some of the rival theories are the telephone theory, the modified telephone theory of Boring, the modified telephone theory of Watt, the volley theory of Wever and Bray, the pattern theory of Ewald, the stationary wave theory, and the resonance theory. At the present day, controversy principally centres round the resonance theory and some form of telephone theory. The production of deafness over a narrow range of frequencies, by surgical interference with a part of the internal ear, is accounted for more readily on the resonance theory than on the rival theory. The same may be said of boilermakers' deafness and its experimentally produced counterpart. When physical tests are applied to hearing, evidence is obtained in each case in favour of resonance and contrary to telephony. The universal acceptance of the resonance theory is delayed by various criticisms, which arise in most cases from unfamiliarity with the behaviour of resonators and sense organs. The resonance theory accounts satisfactorily for all the phenomena, and no other theory does this.

\section{Purpose in Evolution}

In the Riddell Memorial Lectures for 1931, delivered before the University of Durham at Armstrong College, Newcastle-on-Tyne, Sir J. Arthur Thomson discussed the general subject of "Purpose in Evolution" . (Oxford University Press, 1932, pp. 59, 2s. 6d. net). The opening lecture examined various aspects of Nature in view of the question: Is there a purpose in evolution? It grants that often the development and ways of acting of living units are purposive, and comes to the conclusion that the scientific facts do

No. 3262, VoL. 129] 